\title{
Intact stability and seakeeping characteristics of autonomous surface vehicle (asv) using swath hullform to support bathymetry survey activities on the coastal area
}

\author{
Ahmad Fauzan Zakki ${ }^{1,}$, Aris Triwiyatno $^{2}$, Bandi Sasmito $^{3}$, and Muhammad H. Nubly ${ }^{1}$ \\ ${ }^{1}$ Naval Architecture Department, Engineering Faculty, Diponegoro University, Indonesia \\ ${ }^{2}$ Electrical Engineering Department, Engineering Faculty, Diponegoro University, Indonesia \\ ${ }^{3}$ Geodetical Engineering Department, Engineering Faculty, Diponegoro University, Indonesia
}

\begin{abstract}
The information is an important thing to search a new resource. In this decade, with leading-edge technology is easier to find any information about our earth. Thus, that is must be explored by the ships. The exploration works usually take a long time, and for convenience, the unmanned technology is much promised. In this research, we focused on the autonomous surface vehicle for bathymetry survey. To design the ASV, we must consider the reliability, efficiency, and safety. To reach those three components, the analysis of resistance, stability and wave response are necessary. Therefore, the hull form design is focused on Small Waterplane Area Twin Hull (SWATH) hull form. According to the numerical analysis, the proposed SWATH hull form of ASV is suitable for bathymetry activities. It can be proved by the stability performance which the maximum value of GZ is at 26.40. The resistance calculation result is indicated that the drag of coefficient of this hull form is about 0.013 .
\end{abstract}

\section{Introduction}

At the previous time, bathymetry survey was performed by drop down the cables or ropes through the seabed with the ship. However, that technique only limited by once survey per point so that is not efficient. At modern ages, the bathymetry survey can be performed by echo sounding which is attached to the ship side and then radiated the waves. The traveling time of radiated wave from the surface is reflected by seabed and then received. This method was used to calculate the deep of water. As it develops of autonomous surface vehicle (ASV) technology, the role of the ship has been changed by an autonomous vehicle. The marine vehicle is the first vehicle which is using autopilot since 1920's. However, the autopilot which is used on the modern ship is not significantly different with the previous technology, which might not be adapted to the dynamic of the sea environment. The advanced control technology for Unmanned Aerial Vehicle (UAV) and Autonomous Land Vehicle (ALV) is not affected by the marine vehicle. The marine environment is having the difficult characteristic to predict and need more power consumption for propeller system. The prediction of seakeeping performance is necessary, that is for predict the resistance of ship due to responses of waves, [1]. For long distance operational such as oceanography exploration and survey, an ASV which is equipped with power onboard and sophisticated control of navigation are more promising by less human intervention to operate. The robotics technology for the marine vehicle was bringing through to access deep water survey, resource mapping, and military. This ability is precious for an archipelago state which has marine resources.

"Corresponding author: ahmadfzakki@undip.ac.id 
Several articles have been reviewed to support the ASV hull form design using SWATH type hull form. These articles relate to the study of SWATH hull form characteristics and designs and the development of motion controls on ASV. In the development of the SWATH hull form, Gregor Schellenberger, [1] studied the SWATH hull form design method. Parametric studies were performed to obtain optimal SWATH hull form. Some SWATH hull types such as circular shape, Golf Club, and Elephant foot was proposed. Twin Strut or Single strut are also reviewed. The application of the optiSWATH tool is used to obtain the optimum design of the SWATH hull form, [2]. A.E. Baitis et.al presented the seakeeping analysis by comparing monohull, catamaran, and SWATH, [3]. The development study of ASV technology, MIT Sea Grant College Program was developing an Autonomous Surface Craft as known as ARTEMIS, this ASV is a trawler replica, C. Goudey et. al was performed an ASV for the necessity of fish tracking. J.Manley and T.Vaneck were developing a continuous technology of ARTEMIS which is expanded for hydrography survey necessity, [4]. US Navy was shown their interest of ASV by focused on ASV function as transmission equipment for communication support, [5]. Another study, J.Curcio et. al has performed the study of ASV for moving baseline navigation, [6]. The innovative hull form use by using multihull was developed, [7],[8]. Caccia M. was developing SESAMO for sampling on sea surface using semi-submersible hull. H. Ferreira also was developing an ASV using catamaran hull form which named as Swordfish and as known as ROAZ II, [9]. S. Phillips was developing an ASV using semi-submersible hull form for hydrography survey, [10]. W. Sager has performed a study by using the sonar on ASV which is used for hydrography survey, [11]. R. Hine and P. McGillivary have performed a study about wave generator used for the power source of ASV [12]. M. Benjamin was developing a system for ASV collision avoidance, [13].

Based on the reviewed articles above, this research is intended to develop a design for ASV using SWATH hull form to support bathymetry survey. The advantages of SWATH hull form can be expected to obtain the ASV's seakeeping.

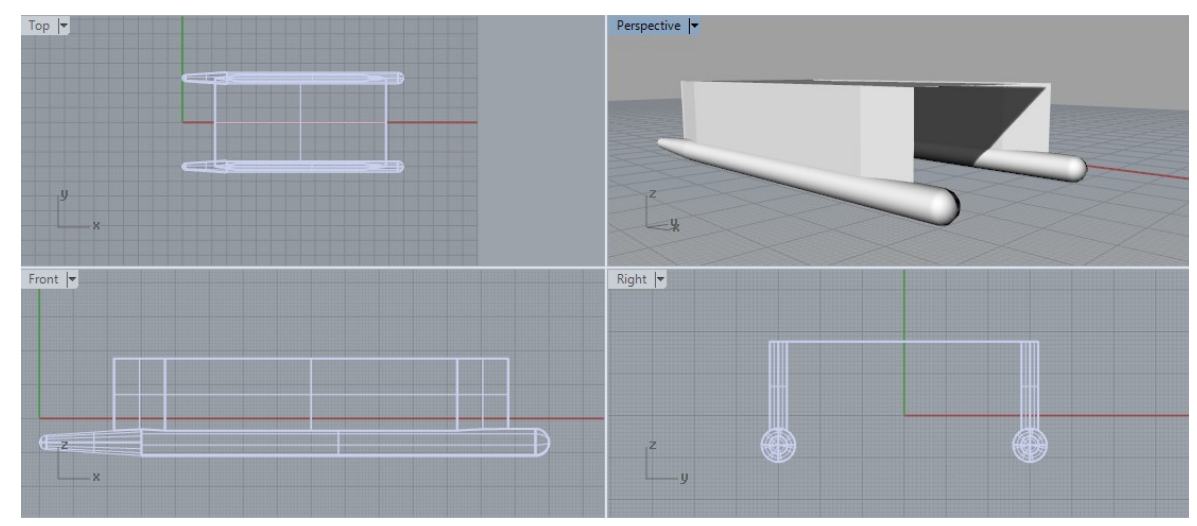

Fig. 1. The 3D model of SWATH Autonomous Surface Vehicle

\section{General designs and concept}

To obtain the principal dimension could be compared the length, breadth, height, draught, and displacement of parent ship. The developed SWATH hull form of the autonomous surface vehicle is shown in the Fig. 1 and the principal dimension can be seen in Table 1. 
Table 1. The principal dimensions of ASV

\begin{tabular}{|c|c|}
\hline \multicolumn{2}{|c|}{ Principal Dimensions } \\
\hline Length & $1500 \mathrm{~mm}$ \\
\hline Breadth & $680 \mathrm{~mm}$ \\
\hline Height & $280 \mathrm{~mm}$ \\
\hline Draught & $110 \mathrm{~mm}$ \\
\hline Displacement $(\Delta)$ & $41.19 \mathrm{Kg}$ \\
\hline
\end{tabular}

\section{Result and discussions}

\subsection{Intact stability characteristics}

Stability calculations were necessary to obtain the GZ moment of the ASV. To calculate it, we need an assumption of the ASV load cases. In each station, must defining the lightship and any stuff which is ASV carried. Distributing the load for each station and finding the point mass. For stability criteria, we are using IMO criteria for general merchant ship (IMO A.749), in intact conditions.

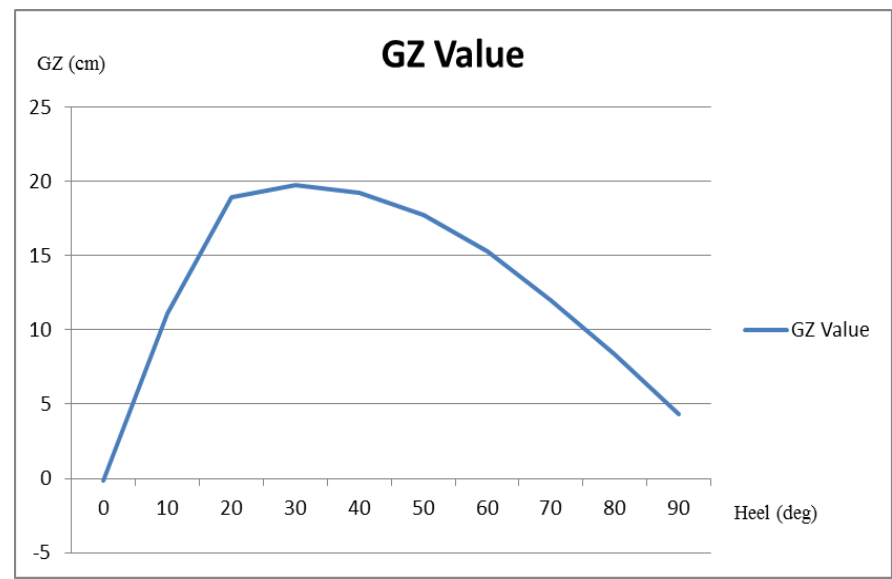

Fig. 2. The GZ curve of the SWATH Autonomous Surface Vehicle Hull Form

The curve as shown in Fig. 2 is explained that the GZ value of ASV still has significant righting moment until $50^{\circ}$ of the heel.

\subsection{Intact stability characteristics}

To predict the engine power of ASV, we must be calculating the resistance. For cruise speed (Vs) we assumed to $1 \mathrm{~m} / \mathrm{s}$ or 1.94 knots. The resistance can be calculated with CFD method. It is necessary to calculate the drag coefficient of ASV. The drag coefficient is a dimensionless quantity that is used to quantify the drag or resistance of an object in the fluid environment. The drag coefficient is always associated with a particular surface area, [14]. The drag coefficient $C_{d}$ is expressed as,

$$
c_{d}=\frac{2 F_{d}}{\rho u^{2} A}
$$


where, $F_{d}$ is the drag force, which is by definition the force component in the direction of flow velocity. $\rho$ is the mass density of the fluid. $u$ is the flow speed of the object relative to the fluid. $A$ is the reference area. The result is shown in Table $\mathbf{2}$,

Table 2. The total drag force at $1 \mathrm{~m} / \mathrm{s}$

\begin{tabular}{|c|c|c|c|}
\hline \multicolumn{5}{|c|}{ Drag Force of ASV } \\
\hline $\begin{array}{c}\text { Reference Area } \\
(\mathbf{m})\end{array}$ & $\begin{array}{c}\text { Drag force of } \\
\text { X-axis (N) }\end{array}$ & $\begin{array}{c}\text { Drag force of } \\
\text { Y-axis (N) }\end{array}$ & $\begin{array}{c}\text { Drag force of } \\
\text { Z-axis (N) }\end{array}$ \\
\hline 8531.46 & 5.55444 & 0.284103 & 0.063112 \\
\hline
\end{tabular}

Table 3. The result of Drag coefficient calculation

\begin{tabular}{|c|c|c|c|c|c|}
\hline \multicolumn{7}{|c|}{ Drag Coefficient of ASV } \\
\hline No. & $\mathbf{u}(\mathbf{m} / \mathbf{s})$ & $\mathbf{u 2}$ & $\mathbf{F d}(\mathbf{N})$ & $\mathbf{A ~ ( m 2 )}$ & $\mathbf{C d}$ \\
\hline 1 & 0.5 & 0.25 & 1.44998 & 0.853146 & 0.0133 \\
\hline 2 & 1 & 1 & 5.55444 & 0.853146 & 0.0127 \\
\hline 3 & 1.5 & 2.25 & 12.2469 & 0.853146 & 0.0124 \\
\hline \multicolumn{7}{|c}{ Average } & 0.013 \\
\hline
\end{tabular}

As shown in Table 3, to obtain the drag coefficient, several simulations should be performed to ensure the estimated value. In this case, the three times simulation was performed with the variation of a service speed of the SWATH ASV. Furthermore, the obtained drag coefficient is about 0.013 .

\subsection{Seakeeping performance}

Seakeeping ability is a measure of how well-suited a vessel is sailing the seaways environment conditions. To define that, we must predict the motions of ASV responses against its environment. The four principal terms needed to describe a seakeeping performance as follow, [15].

1. Mission: the role of the ship while at sea

2. Environment: the conditions under which the ship is operating (sea state)

3. Ship Responses: the response of the ship to the environmental conditions.

4. Seakeeping performance criteria: the established limits for the ship's responses.

The result could be calculated as the RMS (root mean square) of those motions, see Table 4. The root means square is defined as the square root of the mean square (the arithmetic mean of the squares of a set of numbers). According to the area under the response, spectrum delivers the mean of the squared responses, as that under the wave spectrum represent the mean of the derivation squared from zero line, [16]. Hence, the RMS motion is equal to the square of the area under response spectrum.

The roll motion could be interference the bathymetry sensor, which the distance of a transmitted sound would increase from the ASV to the seabed. Thus, the correction of this interference could be calculated as,

$$
Y=\operatorname{arcsec} \phi \cdot h
$$

where $y$ is the extended distance of sound from the ASV to the seabed, $\phi$ is the roll motion and $\mathrm{h}$ is the distance of normal axis. This calculation can be the correction constant of the bathymetry sensor. Where, from the deviation of extended distance and normal distance, 
obtained the correction value. Thus, this correction value would be change along the roll motion value.

Table 4. The motions characteristic of ASV

\begin{tabular}{|l|c|c|}
\hline \multicolumn{1}{|c|}{ Motions } & $\mathbf{9 0}^{\circ}$ & $\mathbf{1 8 0}^{\circ}$ \\
\hline Heave motion $(\mathrm{m})$ & $1.682 \mathrm{E}-01$ & $6.198 \mathrm{E}-01$ \\
\hline Roll motion $(\mathrm{deg})$ & $1.325 \mathrm{E}-02$ & $4.291 \mathrm{E}-04$ \\
\hline Pitch motion $(\mathrm{deg})$ & $7.393 \mathrm{E}-02$ & $7.685 \mathrm{E}-02$ \\
\hline Heave velocity $(\mathrm{m} / \mathrm{s})$ & $1.264 \mathrm{E}-02$ & $4.401 \mathrm{E}-02$ \\
\hline Roll velocity $(\mathrm{rad} / \mathrm{s})$ & $1.058 \mathrm{E}-03$ & $6.120 \mathrm{E}-05$ \\
\hline Pitch velocity $(\mathrm{rad} / \mathrm{s})$ & $3.571 \mathrm{E}-03$ & $1.765 \mathrm{E}-02$ \\
\hline Heave acceleration $(\mathrm{m} / \mathrm{s} 2)$ & $5.033 \mathrm{E}-05$ & $2.920 \mathrm{E}-04$ \\
\hline Roll acceleration $(\mathrm{rad} / \mathrm{s} / \mathrm{s})$ & $1.616 \mathrm{E}-06$ & $1.764 \mathrm{E}-07$ \\
\hline Pitch acceleration $(\mathrm{rad} / \mathrm{s} / \mathrm{s})$ & $4.265 \mathrm{E}-05$ & $6.004 \mathrm{E}-05$ \\
\hline
\end{tabular}

\section{Conclusions}

The autonomous surface vehicles hull form design using Small Waterplane Area Twin Hull was made. The performance of the proposed ASV hull form has been evaluated according to the characteristics of intact stability, resistance, and seakeeping. Based on the result of the numerical analysis, the stability of ASV is accepted by the requirement of bathymetry survey activity. The minimum allowed GZ value is 25.0 , and the actual GZ value is 26.4. The advantage of SWATH hull form is having a small resistance. This will save the power of the engine. And we can install a smaller engine. For Reynold number is about $9.97 \times 10^{8}$, and the ITTC experiment for $\mathrm{Rn}=10^{9}$ is about 0.015 for drag coefficient. The ASV has smaller drag coefficient in the amount of 0.013 . The motion behaviors would be limited the ASV cruise area only in the coastal area or inland waterways. The echo sound deviation result which is caused by roll motion could be calibrated by determining the roll angle during the depth measurement.

\section{Acknowledgments}

The work is funded by Directorate of Research and Community Services (DRPM) of the Indonesian Ministry of Research, Technology and Higher Education under the scheme of the excellent applied research of university - (Penelitian Terapan Unggulan Perguruan Tinggi) PTUPT program.

\section{References}

1. Iqbal M, Rindo G, KAPAL 12 19-24, (2015)

2. Schellenberger G., SWATH Technology Advanced SWATH Design Methods (ThyssenKrupp Marine Systems) (2007)

3. Baitis A E, Meyers W G, Woolaver D A, Lee C M, A seakeeping comparison between three monohulls, Two SWATH, and a Column-Stabilized Catamaran Design for The Same Mission (Naval Ship Research and Development Center), (1975)

4. Vaneck T, Manley J, Rodriguez C, Schmidt M, Journal of the Institute of Navigation 43, (1997)

5. U.S. Navy, Available online:www.navy.mil/navydata/technology/usvmppr.pdf (2007)

6. Curcio J, Leonard J, Vaganay J, Patrikalakis A, Bahr A, Battle D, Schmidt H, Grund M Proc. of Oceans 2005 (2005) 
7. Ferreira H, Martins A, Dias A, Almeida C, Almeida J M, Silva E P, Encontro Científico - Robótica (2006)

8. Caccia M, Bono R, Bruzzone G, Bruzzone G, Spirandelli E, Veruggio G, Stortini A M, Capodaglio G, Robotics and Automation Magazine 1295 (2005)

9. Ferreira H, Martins R, Marques E, Pinto J, Martins A O, Almeida J M, Sousa J B, Silva E P, Proc. of the Oceans Europe'07 Conference (2007)

10. Phillips S, Hook D, Young H, Proc. of UDT Europe 2008(2008)

11. Sager W, Shyu J, Manley J, Sea Technology 49 (2008)

12. Hine R, McGillivary P, Proc.of PACON 2007 (2007)

13. Benjamin M, Curcio J, Leonard J, Newman P, Journal of Field Robotics 23 (2006)

14. McCormick, Barnes W, Aerodynamics, Aeronautics, and Flight Mechanics, (John Wiley \& Sons, Inc.) p 24 (1979)

15. Faltinsen O M, Hydrodynamics of High-Speed Marine Vehicles (Cambridge University Press) p 6 (2005)

16. Bhattacharyya R, Dynamics of Marine Vehicles (John Wiley \& Sons. Inc, New York) (1978) 